УДК 544.6.018

\title{
ФИЗИКО-ХИМИЧЕСКИЕ СВОЙСТВА СУЛЬФАТНО-ГЛИЦИНАТНЫХ РАСТВОРОВ ЦИНКОВАНИЯ
}

\author{
(C) 2017 Е. В. Ченцова, С. Ю. Почкина, Н. Д. Соловьева
}

Энгельсский технологический институт (филиал) ФГБОУ ВО «Саратовский государственньй технический университет имени Ю. А. Гагарина», пл. Свободьл, 17, 413100 Энгельс, Саратовская обл., Россия

e-mail:tepeti@mail.ru; ev-mail@rambler.ru;pochkina_s@mail.ru

Поступила в редакцию 17.02.2017

\begin{abstract}
Аннотация. Изучены физико-химические свойства сульфатно - глицинатных электролитов, проведена оценка взаимодействия компонентов в изучаемых растворах цинкования при содержании $\mathrm{ZnSO}_{4}$ 0.05-0.25 моль/л, $\mathrm{NH}_{2} \mathrm{CH}_{2} \mathrm{COOH}$ 0.6-0.95 моль/л в диапазоне температур 22$55{ }^{\circ} \mathrm{C}$. На основании анализа зависимости электропроводности, оптической плотности, вязкости и энтальпии вязкого течения от состава растворов обоснован выбор концентраций компонентов модельного электролита цинкования.
\end{abstract}

Ключевые слова: электролит цинкования, глицин, электропроводность, оптическая плотность, энтальпия активации вязкого течения, комплексообразование, координационное число.

\section{ВВЕДЕНИЕ}

В качестве защитных покрытий для изделий из стали от коррозионного разрушения широкое применение нашли покрытия цинком и сплавами на его основе. Получение покрытий осуществляется из электролитов различного состава [1-6]. Для выбора оптимальных технологических параметров электроосаждения металлов необходимо изучить процессы, происходящие в растворах электролитов, определить рабочий диапазон концентраций. Известен ряд работ [6-12], в которых в качестве буферного и комплексообразующего компонента при электроосаждении металлов в состав электролита вводится глицин. Интерес исследователей к использованию глицина в различных электрохимических системах обусловлен уникальностью его свойств и поведения в водных растворах. В зависимости от кислотности раствора глицин сочетает в себе электронодонорные, мостиковые (медиаторные) и буферные свойства. Биполярный характер ионов глицина в водных растворах обусловливает возможность адсорбции их как на положительно, так и на отрицательно заряженных поверхностях электрода [12-14]. Присутствие в электролитах цинкования комплексных соединений $\mathrm{ZnGly}^{+}$и $\mathrm{Zn}(\mathrm{Gly})_{2}$, образованных глицином [10], способствует получению мелкозернистого равномерного блестящего покрытия.
Структура водных растворов определяется совокупностью взаимодействий между компонентами. Вследствие заполненности $d$-уровней у цинка (II) в его комплексных соединениях отсутствует эффект стабилизации полем лигандов. Стереохимия его соединений определяется размером иона, электростатическими силами и ковалентностью связей. При переходе от аквакомплексов $d$-элементов к аминокомплексам устойчивость комплекса возрастает. Процесс образования аминокомплексов $d$-элементов в водных растворах рассматривается как реакция последовательного замещения молекул воды во внутренней сфере аквакомплексов на ионы аминоуксусной кислоты [10].

Процесс сольватации аминокислот характеризуется широким спектром межмолекулярных сил: от слабых ван-дер-ваальсовых до сильных дипольдипольных взаимодействий и водородных связей, а также обусловлен их цвиттер-ионным строением. Сложность анализа таких систем определяется зависимостью поведения аминокислот в растворах от влияния многих факторов, таких как $\mathrm{pH}$, тип присутствующего электролита и его концентрация, температура $[12,15,16]$. Данные о влиянии концентрации компонентов сульфатно-глицинатного раствора на процесс комплексообразования в электролитах цинкования неоднозначны $[6,10-12]$.

Цель данной работы состояла в изучении физико-химических и термодинамических свойств рас- 
творов и обосновании выбора концентраций компонентов модельного электролита цинкования.

\section{ЭКСПЕРИМЕНТАЛЬНАЯ ЧАСТЬ}

В работе исследовали сульфатные и сульфатно-глицинатные растворы: 1 - $\mathrm{Na}_{2} \mathrm{SO}_{4} 0.5$ моль/л + $\mathrm{NH}_{2} \mathrm{CH}_{2} \mathrm{COOH} 0.6 \ldots 0.95$ моль/л; $2-\mathrm{ZnSO}_{4}$ $0.05 \ldots 0.25$ моль/л $+\mathrm{Na}_{2} \mathrm{SO}_{4} 0.5$ моль/л; $3-\mathrm{ZnSO}_{4}$ $0.05 \ldots 0.25$ моль/л $+\mathrm{Na}_{2} \mathrm{SO}_{4} 0.5$ моль/л + $\mathrm{NH}_{2} \mathrm{CH}_{2} \mathrm{COOH} 0.7$ моль/л. Для приготовления растворов использовали реактивы марки «х. ч.» и дистиллированную воду. Величину $\mathrm{pH}$ растворов доводили до $5.5 \pm 0.1$ с помощью $\mathrm{NaOH}$, контролировали $\mathrm{pH}$-метром «Эксперт-рН». В изучаемых электролитах определяли вязкость, плотность и электропроводность в диапазоне температур от 22 до $55^{\circ} \mathrm{C}$. Поддержание температуры растворов осуществлялось термостатом U-15 с точностью $\pm 0.5^{\circ} \mathrm{C}$. Кинематическую вязкость электролитов (v) измеряли вискозиметром ВПЖ-2м с диаметром капилляра 0.56 мм, электропроводность (æ) - кондуктометром лабораторным КЛ-С-1, плотность ( $\rho)$ набором денсиметров АОН-1 $[17,18]$. Проводили 3-4 параллельных опыта. Воспроизводимость экспериментальных результатов оценивали с помощью критерия Кохрена при использовании трех выборок результатов эксперимента. Рассчитанные доверительные интервалы представлены на кривых концентрационной зависимости электропроводности и кинематической вязкости растворов. Расчет кинематической вязкости (v) проводился по уравнению: $v=\tau \cdot k$ (где $\tau-$ время истечения, с; $k$ - постоянная вискозиметра, $\left.\mathrm{Mм}^{2} / \mathrm{c}^{2}\right)$. Измерение потенциала цинкового электрода осуществлялось с помощью вольтметра GDM-8135 с точностью \pm 0.001 В относительно хлоридсеребряного электрода сравнения (0.222 В относительно н. В. э.). Использовался цинк марки Ц1. Измерение оптической плотности растворов проводили спектрофотометрическим методом с помощью фотометра КФК-3-01 при использовании стеклянной ячейки с толщиной поглощающего слоя 3 см. Длины волн устанавливали в области 300-900 нм с погрешностью \pm 0.1 нм.

\section{РЕЗУЛЬТАТЫ И ИХ ОБСУЖДЕНИЕ}

Для оценки взаимодействия компонентов в сульфатно-глицинатном растворе цинкования проводилось последовательное их смешение и определение вязкости, плотности, электропроводности в изучаемом диапазоне температур. В электролите цинкования сульфат натрия выполняет роль электропроводной добавки. В исследуемых растворах его содержание было постоянно и составляло 0.5 моль/л. Введение в водный раствор 0.5 моль/л $\mathrm{Na}_{2} \mathrm{SO}_{4}$ сульфата цинка в количестве 0.05 моль/л практически не сказывается на электропроводности раствора, но дальнейший рост концентрации $\mathrm{ZnSO}_{4}$ до 0.25 моль/л приводит к постепенному снижению æ (рис. 1a, кривая 1). Снижению электропроводности растворов соответствует рост кинематической вязкости до концентрации сульфата
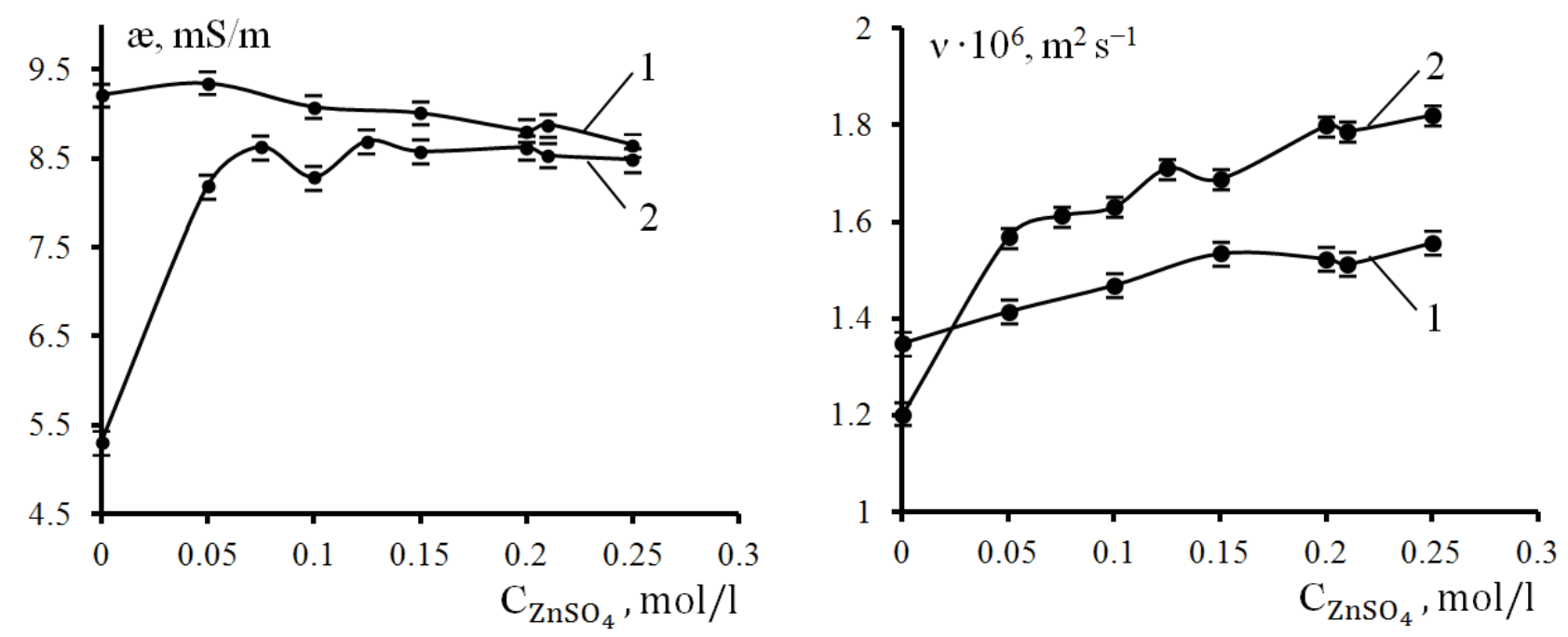

Рис. 1. Влияние концентрации сульфата цинка на электропроводность $(a)$ и кинематическую вязкость $(b)$ электролита состава, моль/л: $1-\mathrm{ZnSO}_{4} \mathrm{X}, \mathrm{Na}_{2} \mathrm{SO}_{4} \quad 0.5 ; 2-\mathrm{ZnSO}_{4} \mathrm{X}, \mathrm{Na}_{2} \mathrm{SO}_{4} \quad 0.5, \mathrm{NH}_{2} \mathrm{CH}_{2} \mathrm{COOH} 0.7$

[Fig. 1. Effect of zinc sulphate concentration on the electrical conductivity $(a)$ and kinematic viscosity $(b)$ of the composition electrolyte, mol/1: $\left.1-\mathrm{ZnSO}_{4} \mathrm{X}, \mathrm{Na}_{2} \mathrm{SO}_{4} \quad 0.5 ; 2-\mathrm{ZnSO}_{4} \mathrm{X}, \mathrm{Na}_{2} \mathrm{SO}_{4} \quad 0.5, \mathrm{NH}_{2} \mathrm{CH}_{2} \mathrm{COOH} 0.7\right]$ 
цинка 0.15 моль/л (рис. $1 b$, кривая 1). В диапазоне концентраций $\mathrm{ZnSO}_{4}$ от 0.175 до 0.25 моль/л величины вязкости раствора и его проводимости колеблются около среднего значения: $v \sim 1.52 \cdot 10^{-6} \mathrm{M}^{2} \cdot \mathrm{c}^{-1}$, $æ \sim 8.90 \mathrm{мCм} / \mathrm{м}$ (рис. 1, кривые 1). Изменения æ и $v$ в изучаемом концентрационном диапазоне исследуемых растворов могут быть связаны с конкурирующим структуроразрушающим и структурообразующим действием ионов $\mathrm{Zn}^{2+}$ и $\mathrm{SO}_{4}^{2-}$ на структуру воды. Разрушение структуры воды связано с разрывом водородных связей, повышением содержания свободных молекул воды, которые связываются в гидратные комплексы ионами $\mathrm{Zn}^{2+}$ и $\mathrm{SO}_{4}^{2-}$.

Согласно литературным данным $[19,20]$, для указанных растворов характерно образование комплексов типа $\left[\mathrm{Zn}\left(\mathrm{H}_{2} \mathrm{O}\right)_{5}\right]^{2+}$, контактных пар вида $\left[\mathrm{Zn}\left(\mathrm{H}_{2} \mathrm{O}\right)_{5}\right]^{2+} \cdot \mathrm{SO}_{4}^{2-[20]}$, а также неконтактных ионных пар между катионами и анионами. Появление данных соединений приводит к снижению проводимости раствора и некоторому возрастанию вязкости. Анализ концентрационной зависимости удельной электропроводности и вязкости водных растворов $\mathrm{Na}_{2} \mathrm{SO}_{4} 0.5$ моль/л $+\mathrm{ZnSO}_{4} \mathrm{X}$ моль/л позволил выделить диапазон концентраций соли цинка от 0.20 до 0.25 моль/л, в котором не наблюдается изменений вязкости и проводимости растворов, что является важным для стабильной работы электролитов при электроосаждении покрытий.

С целью выбора концентрации буферирующей и комплексообразующей добавки глицина определяли ее влияние на электропроводность водного раствора $\mathrm{Na}_{2} \mathrm{SO}_{4} 0.5$ моль/л $+\mathrm{NH}_{2} \mathrm{CH}_{2} \mathrm{COOH} \mathrm{Х} \mathrm{моль/л.}$ Введение глицина приводит к снижению удельной электропроводности $0.5 \mathrm{M}$ раствора сульфата натрия (рис. $1 a, 2 a$ ), которая равна $9.25 \mathrm{mCM} / \mathrm{M}$ (рис. 1a). Величина $\mathrm{pH}$ исследованных растворов находится ниже $\mathrm{pH}$ изоэлектрической точки глицина $\left(\mathrm{pH}_{\text {и }}=6.1\right)$ [13]. Следовательно, предпочтительными формами глицина в растворе являются биполярная ${ }^{+} \mathrm{H}_{3} \mathrm{~N}-\mathrm{CH}_{2}-\mathrm{COO}^{-}$и монополярная ${ }^{+} \mathrm{H}_{3} \mathrm{~N}-\mathrm{CH}_{2}-\mathrm{COOH}$. Стабильность глицина в воде определяется взаимодействием растворенное вещество-растворитель. Цвиттерионная форма глицина включает в себя две гидрофильные $-\mathrm{NH}_{3}^{+}$, $-\mathrm{COO}^{-}$и одну гидрофобную $-\mathrm{CH}_{2}-$ группы [21]. Способность к образованию водородных связей $\left(\mathrm{N} \cdots \mathrm{H}_{\text {вода }}-\mathrm{O}_{\text {вода }}\right.$ и $\left.\mathrm{N}-\mathrm{H} \cdots \mathrm{O}_{\text {вода }}, \mathrm{O}^{-} \ldots \mathrm{OH}_{\text {вода }}\right)$ оказывает влияние на геометрию молекулы и на термодинамические характеристики гидратации глицина [22-24]. В работе [24] произведен расчет структуры гидратной оболочки Gly при бесконечном разведении. Было вычислено, что полное гидратное число глицина составляет $\sim 17$. В ближнем окружении $-\mathrm{NH}_{3}{ }^{+}-$группы находится $\sim 5$ молекул воды, из них 2 молекулы воды $\mathrm{H}-$ связаны $\mathrm{c}-\mathrm{NH}_{3}{ }^{+}$группой, $\mathrm{H}-$ связывание атома азота группы $-\mathrm{NH}_{3}^{+}$с молекулами воды отсутствует. В ближнем окружении $-\mathrm{COO}^{-}$группы находится $\sim 6$ молекул воды, Н-связанных $\mathrm{c}-\mathrm{COO}^{-}$группой. В ближнем окружении - $\mathrm{CH}_{2}$ группы присутствует $\sim 6$ молекул воды. Информация по значению гидратного числа глицина неоднозначна. В ряде работ приводятся данные, что для стабилизации цвиттер-ионной формы глицина необходимо окружить ее молекулами воды от 2 до 17 [24-26], что связано с разным подходом авторов к определению значения гидратного числа.

Величина гидратного числа зависит от состава и концентрации раствора: при увеличении концентрации растворенного вещества гидратное число снижается [27]. Происходящие структурные изменения раствора отражаются в величине физикохимических свойств исследуемых растворов. Максимум электропроводности и минимум вязкости соответствуют содержанию глицина в растворе 0.7 моль/л (рис. 2). При концентрации 0.93 моль/л отмечается некоторый рост удельной электропроводности при практически не изменяющейся вязкости раствора. Это может быть связанно с тем, что происходит перераспределение молекул воды в ближайшем окружении глицина, что приводит к уменьшению его гидратного числа.

При подборе состава электролита цинкования была использована концентрация глицина 0.7 моль/л, для которой в водном растворе 0.5 моль/л $\mathrm{Na}_{2} \mathrm{SO}_{4}$ наблюдается максимум электропроводности. Установлено, что при введении глицина в электролит, содержащий $\mathrm{Na}_{2} \mathrm{SO}_{4} 0.5$ моль/л + $\mathrm{ZnSO}_{4} \mathrm{X}$ моль/л, наблюдается снижение электропроводности и рост кинематической вязкости, что может быть обусловлено структурными изменениями в растворе (рис. 1, кривые 2). Данные изменения физико-химических свойств растворов могут быть связанны с образованием комплексов ионов цинка с глицином. Существование комплексов ионов цинка с глицином было установлено авторами [10-12] в растворах, содержащих соли цинка концентрации от 0.005 до 0.5 моль/л и глицин от 0.05 до 2.0 моль/л. Для изучаемого концентрационного диапазона компонентов электролитов на основании полученных результатов по физико-химическим и оптическим свойствам (рис. 3) также можно говорить о присутствии комплексов. Это находит отражение в скачкообразном увеличении $v$, мало меняющимся значениям æ при росте концентра- 

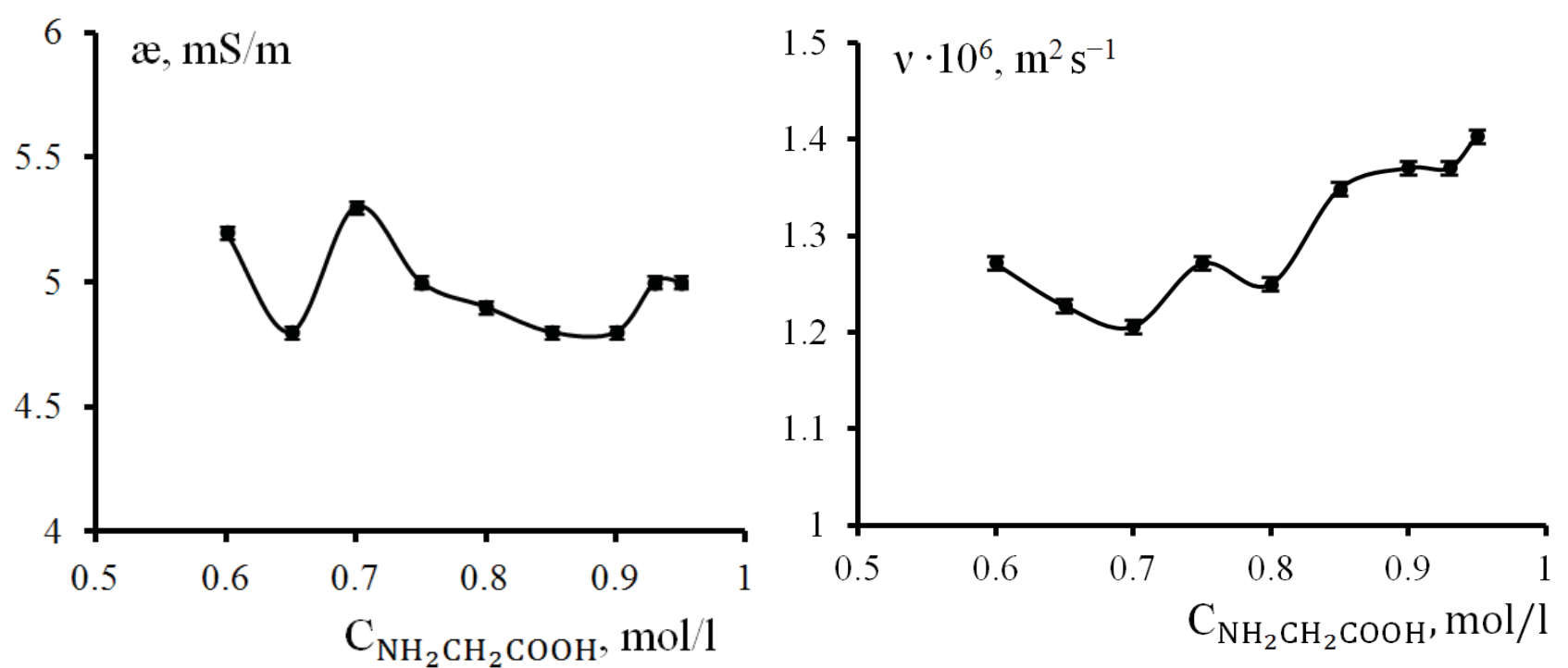

Рис. 2. Влияние концентрации глицина на электропроводность $(a)$ и кинематическую вязкость $(b)$ раствора состава, моль/л: $\mathrm{Na}_{2} \mathrm{SO}_{4} 0.5, \mathrm{NH}_{2} \mathrm{CH}_{2} \mathrm{COOH} \mathrm{X}$

[Fig. 2. Effect of glycine concentration on the electrical conductivity $(a)$ and kinematic viscosity $(b)$ of the composition solution, $\mathrm{mol} / \mathrm{l}: \mathrm{Na}_{2} \mathrm{SO}_{4} 0.5, \mathrm{NH}_{2} \mathrm{CH}_{2} \mathrm{COOH} \mathrm{X]}$

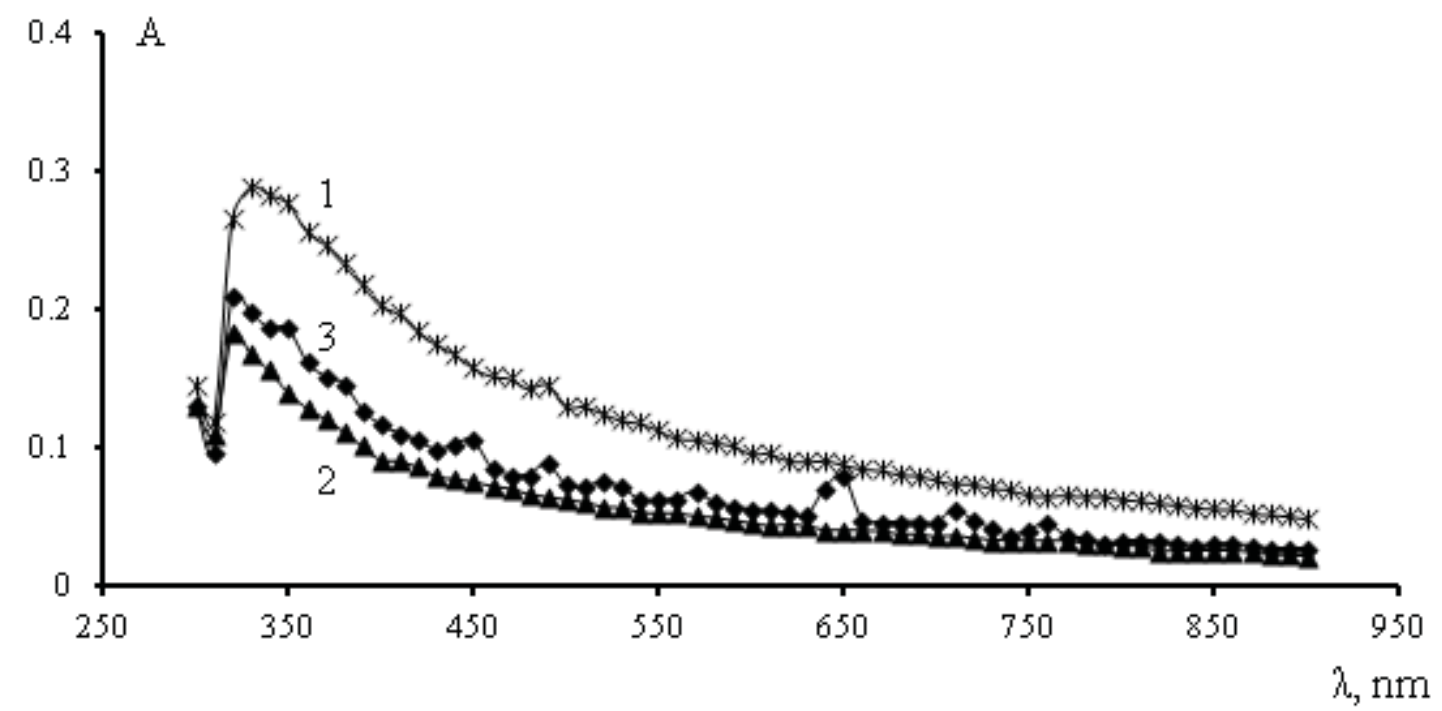

Рис. 3. Влияние длины волны светового потока на оптическую плотность раствора состава, моль/л: $1-\mathrm{Na}_{2} \mathrm{SO}_{4}$ $0.50, \mathrm{NH}_{2} \mathrm{CH}_{2} \mathrm{COOH} 0.70 ; 2-\mathrm{ZnSO}_{4} 0.21, \mathrm{Na}_{2} \mathrm{SO}_{4} 0.50 ; 3-\mathrm{ZnSO}_{4} 0.21, \mathrm{Na}_{2} \mathrm{SO}_{4} 0.50, \mathrm{NH}_{2} \mathrm{CH}_{2} \mathrm{COOH} 0.7$

[Fig. 3. Influence of the light flux wavelength on the optical density of the composition solution, mol/l: $1-\mathrm{Na}_{2} \mathrm{SO}_{4} 0.50$, $\left.\mathrm{NH}_{2} \mathrm{CH}_{2} \mathrm{COOH} 0.70 ; 2-\mathrm{ZnSO}_{4} 0.21, \mathrm{Na}_{2} \mathrm{SO}_{4} 0.50 ; 3-\mathrm{ZnSO}_{4} 0.21, \mathrm{Na}_{2} \mathrm{SO}_{4} 0.50, \mathrm{NH}_{2} \mathrm{CH}_{2} \mathrm{COOH} 0.7\right]$

ции сульфата цинка (рис. 1, кривые 2). Некоторый вклад в снижение величины оптической плотности глицинатного раствора при введении сульфата цинка (рис. 3) также может оказывать эффект уменьшения мольного объема группы $-\mathrm{CH}_{2}-$, повышение содержания сульфат-ионов, оказывающих обезвоживающее действие на заряженные группы глицина [28].
Используя подход Эйринга [28] к расчету термодинамических характеристик растворов, проводился анализ температурной зависимости кинематической вязкости изучаемых электролитов в полулогарифмических координатах $\lg v, 1 / T$ (рис. 4). В исследованных растворах на кривых $\lg v$, $1 / T$ выделяются два участка с различным углом наклона в области температур 22-35 ${ }^{\circ} \mathrm{C}$ и 40- 


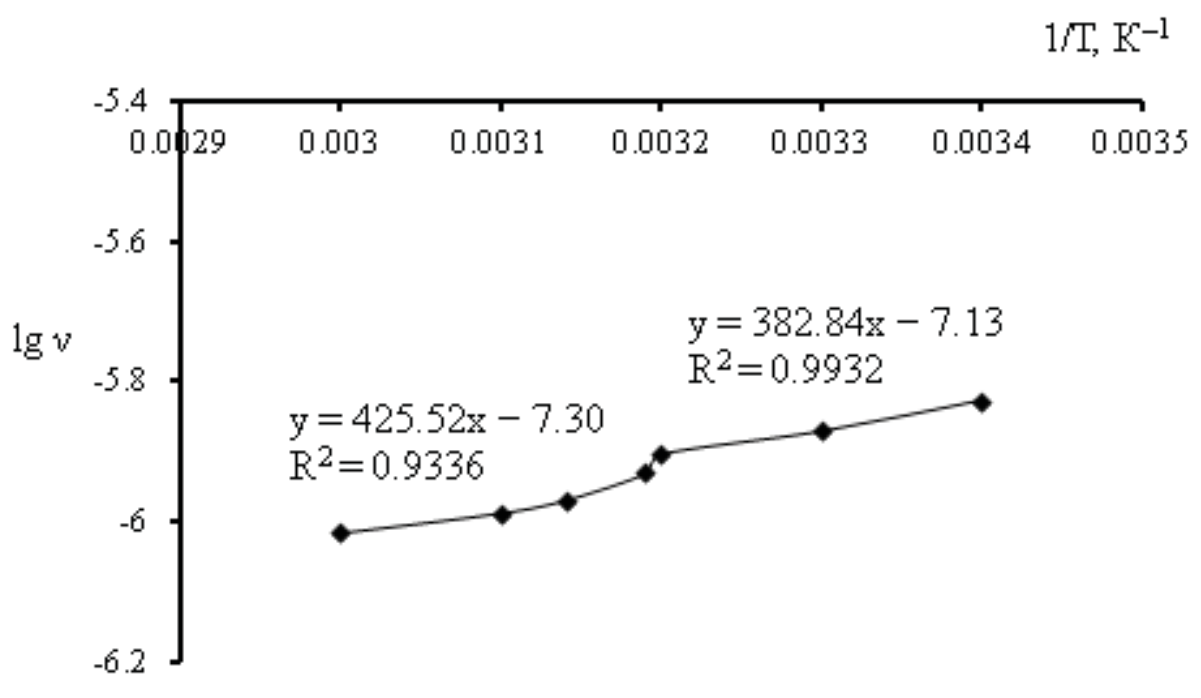

Рис. 4. Зависимость $\lg v, 1 / T$ для электролита состава, моль/л: $\mathrm{ZnSO}_{4} 0.21, \mathrm{Na}_{2} \mathrm{SO}_{4} 0.50, \mathrm{NH}_{2} \mathrm{CH}_{2} \mathrm{COOH} 0.7$

[Fig. 4. Dependence of $\lg v, 1 / T$ for composition electrolyte, mol/1: $\left.\mathrm{ZnSO}_{4} 0.21, \mathrm{Na}_{2} \mathrm{SO}_{4} 0.50, \mathrm{NH}_{2} \mathrm{CH}_{2} \mathrm{COOH} 0.7\right]$

$55^{\circ} \mathrm{C}$. Известно, что конкурирующее действие структуроразрушающих и стабилизирующих факторов, к которым относятся природа вводимых компонентов, их концентрация и температура раствора, оказывает влияние на структуру воды и образующегося электролита. Это находит отражение в величине энтальпии активации вязкого течения $\left(\Delta H^{*}\right)$, рассчитанной по уравнению:

$$
\Delta H^{*}=2.3 R \frac{\Delta \lg v}{\Delta(1 / T)} .
$$

Полученные величины энтальпии активации вязкого течения растворов: $\mathrm{Na}_{2} \mathrm{SO}_{4} 0.5$ моль/л + $\mathrm{NH}_{2} \mathrm{CH}_{2} \mathrm{COOH} \mathrm{X}(\mathrm{X}=0.7 ; 0.93 ; 0.95)$ моль/л; $\mathrm{ZnSO}_{4}$ 0.21 моль/л $+\mathrm{Na}_{2} \mathrm{SO}_{4} 0.5$ моль/л $+\mathrm{NH}_{2} \mathrm{CH}_{2} \mathrm{COOH}$ 0.7 моль/л и $\mathrm{ZnSO}_{4} 0.21$ моль/л $+\mathrm{Na}_{2} \mathrm{SO}_{4} 0.5$ моль/ л лежат в пределах $5.1 \ldots 10.5$ кДж/моль в диапазоне температур $22-55^{\circ} \mathrm{C}$, что свидетельствует о преобладании разупорядочивания в структуре воды (величина $\Delta H^{*}$ воды 16.26 кДж/моль [29]). При введении в электролит $\mathrm{Na}_{2} \mathrm{SO}_{4} 0.5$ моль/л + $\mathrm{NH}_{2} \mathrm{CH}_{2} \mathrm{COOH} 0.7$ моль/л сульфата цинка в количестве 0.21 моль/л происходит увеличение $\Delta H^{*}$ от 5.9 кДж/моль до 7.3 кДж/моль в диапазоне температур $22-35^{\circ} \mathrm{C}$, что позволяет говорить о повышении структурирования раствора вследствие образования глицинатных комплексов цинка. Увеличение температуры раствора до $40^{\circ} \mathrm{C}$ и выше в электролите состава $\mathrm{ZnSO}_{4} 0.21$ моль/л $+\mathrm{Na}_{2} \mathrm{SO}_{4} 0.5$ моль/ л $+\mathrm{NH}_{2} \mathrm{CH}_{2} \mathrm{COOH} 0.7$ приводит к снижению $\Delta H^{*}$ до $\sim 6.4$ кДж/моль. Согласно работам Н. Б. Березина и сотр. [10], комплексы ZnGly+ относятся к нестабильным соединениям, константа устойчивости которых составляет $2.4 \cdot 10^{-3}$. Соответственно можно предположить, что при температурах, превышающих $35^{\circ} \mathrm{C}$, протекает распад глицинатных комплексов цинка.

Для определения координационного числа $(n)$ в образующемся комплексе использовался потенциометрический метод, предложенный Кравцовым [30]. Согласно данному подходу измерялся потенциал цинкового электрода $\left(E_{1}\right)$ в электролите 1 $\left(\mathrm{Na}_{2} \mathrm{SO}_{4} 0.50\right.$ моль/л $+\mathrm{ZnSO}_{4}$ Х моль/л) и в электролите 2 с введением глицина в количестве 0.7 моль/ л $\left(E_{2}\right)$. Построение зависимости $\Delta E, \ln C_{\mathrm{Zn}^{2+}}$, где $\Delta E=E_{2}-E_{1}$, позволило определить $\operatorname{tg} \beta=\frac{\Delta E}{\Delta \ln C_{\mathrm{Zn}^{2+}}}$ и рассчитать $n=\frac{z F \operatorname{tg} \beta}{R T}$, где $z$ - валентность ионов цинка, $F$ - постоянная Фарадея, $R$ - газовая постоянная, $T$ - температура (рис. 5).

Согласно расчетам величина $n=1.05 \approx 1$ для диапазона концентраций соли цинка от 0.10 до 0.21 моль/л. Следовательно, в изучаемом диапазоне концентраций соли цинка при содержании глицина $0.7 \mathrm{M}$ образуются комплексные соединения типа ZnGly ${ }^{+}$при $t=25{ }^{\circ} \mathrm{C}$ (pH раствора 5.5). Наклон кривой $\Delta E$, резко уменьшается при температуре, превышающей $40{ }^{\circ} \mathrm{C}$ (рис. 5), что подтверждает нестабильность глицинатных комплексов цинка при повышении температуры. 


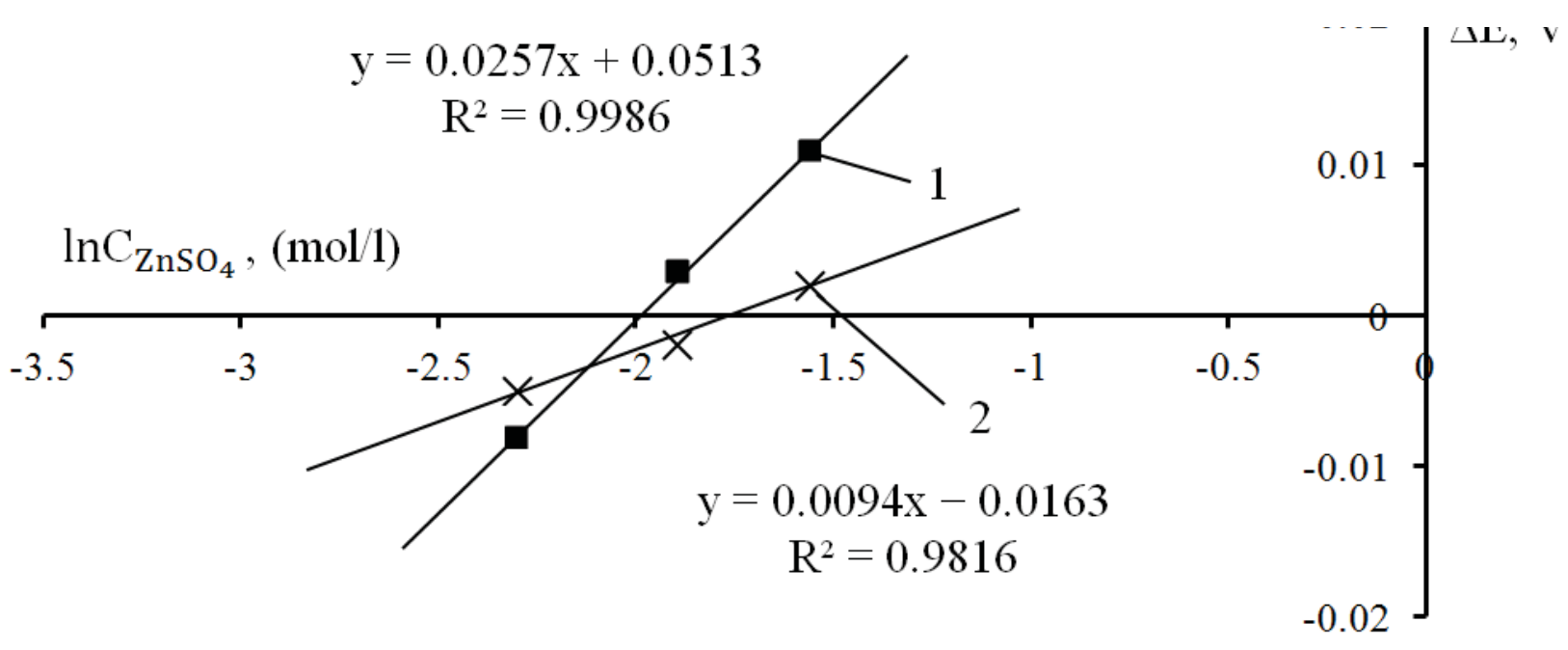

Рис. 5. Зависимость $\Delta E, \ln C_{\mathrm{ZnSO}_{4}}$ для цинкового электрода в сульфатно-глицинатных растворах цинкования при $25^{\circ} \mathrm{C}(1)$ и $45^{\circ} \mathrm{C}(2)$

[Fig. 5. Dependence of $\Delta E, \ln C_{\mathrm{ZnSO}_{4}}$ for a zinc electrode in sulfate-glycine solutions for electroplating of zinc at $25^{\circ} \mathrm{C}(1)$ and $\left.45^{\circ} \mathrm{C}(2)\right]$

\section{ЗАКЛЮЧЕНИЕ}

Физико-химические свойства сульфатно-глицинатных электролитов цинкования определяются структурными изменениями в растворах, связанными с образованием глицинатных комплексов цинка. Установлено, что в диапазоне концентраций сульфата цинка от 0.10 до 0.21 моль/л при содержании глицина 0.7 моль/л образуется комплекс с координационным числом равным $1-\mathrm{ZnGly}^{+}$.

Устойчивость образовавшегося комплекса зависит от температуры. О влиянии температуры на структурные превращения в электролите указывает и снижение энтальпии активации вязкого течения от $\sim 7.3$ кДж/моль (диапазон $22-35{ }^{\circ} \mathrm{C}$ ) до $\sim 6.4$ кДж/моль (диапазон $40-55{ }^{\circ} \mathrm{C}$ ). Образование в электролите цинкования глицинатных комплексов типа $\mathrm{ZnGly}^{+}$должно способствовать получению равномерных, мелкозернистых осадков. Учитывая возможность образования комплексов цинка в диапазоне концентраций $\mathrm{ZnSO}_{4}$ от 0.10 до 0.21 моль/л, а также величины электропроводности и вязкости изучаемых растворов, для электроосаждения цинка был рекомендован электролит состава: $\mathrm{ZnSO}_{4} 0.21$ моль/л, $\mathrm{Na}_{2} \mathrm{SO}_{4} 0.5$ моль/л, $\mathrm{NH}_{2} \mathrm{CH}_{2} \mathrm{COOH} 0.7$ моль/л.

\section{СПИСОК ЛИТЕРАТУРЫ}

1. Окулов В. В. Цинкование. Техника и технология. М.: Глобус, 2008, 252 с

2. Шеханов Р. Ф., Гридчин С. Н., Балмасов А. В., Румянцева К. Е. // Изв. вузов. Химия и химическая технология, 2015, т. 58, вып. 1, с. 104-106.
3. Бобрикова И. Г., Гончаренко Е. Г., Шахлевич Е. С. // Современные тенденции развития науки и технологий, 2016, № 3-3, с. 28-31.

4. Шмидт В. В., Жихарева И. Г., Ракашов А. А. // Научно-технический вестник Поволжья, 2015, № 3, c. 74-78.

5. Micin S., Martinez S., Malinovic B., Grozdanic V. // Journal of Chemical Technology and Metallurgy, 2016, vol. 51, № 5, pp. 556-562.

6. Березин Н. Б., Березина Т. Н., Межевич Ж. В., Сысоев В. А. // Вестник технологического университе$m a, 2014$, т. 17, № 22, с. 355-359.

7. Петрушова О. Ю., Цупак Т. Е. // Успехи в химии и химической технологии, 2014, т. XXVIII, № 5, с. 9597.

8. Долгих О. В., Соцкая Н. В., Шаманаева Е. С. // Конденсированные среды и межффазные границы, 2007, т. 9, № 1, c. 32-39.

9. Сапронова Л. В., Соцкая Н. В., Долгих О. В. // Конденсированные среды и межфазные границы, 2013, т. 15 , № 4, с. 446-452.

10. Березин Н. Б., Березина Т. Н., Межевич Ж. В., Чевела В. В. // Вестник технологического университе$m a, 2013$, т. 16, № 5, с. 267-268.

11. Козихонов А. У., Джулаев У. Н., Раджабов У. Р., Шухратзода М., Бобиев Г. М. // Доклады Академии наук Республики Таджикистан, 2015, т. 58, № 7, с. 608-614.

12. Березин Н. Б., Гудин Н. В., Филиппова А. Г., Чевела В. В., Межевич Ж. В., Яхьяев Э. Д., Сагдеев К. А. Электроосаждение металлов и сплавов из водных растворов комплексных соединений. Казань, Изд-во Казан. гос. технол. ун-та, 2006, 276 с.

13. Межевич Ж. В., Березин Н. Б. // Вестник технологического университета, 2016, т. 19, № 9, с. 51-53. 
14. Кращенко Т. Г., Введенский А. В., Бобринская Е. В., Кулешова Н. Е. // Конденсированные среды и межфазные гранищьы, 2014, т. 16, № 1, с. 42-49.

15. Хохлов В. Ю., Селеменев В. Ф., Хохлова О. Н., Загородний А. А. // Вестник ВГУ. Серия химия, биология, фармаичия, 2003, № 1, с. 18-22.

16. Бобрешкова О. В., Полуместная К. А., Федосова А. А. // Электрохимия, 2009, т. 45, № 3, с. 367-371.

17. Абросимов В. К., Королев В. В., Афанасьев В. Н. и др. / отв. ред. Кутепов А. М. Экспериментальные методы химии растворов: денситометрия, вискозиметрия, кондуктометрия и другие методь. М.: Наука, 1997, $351 \mathrm{c.}$

18. Соловьева Н. Д., Фролова И. И., Легкая Д. А. // Конденсированные среды и межфазные границь, 2014, т. 16, № 2, с. 201-205.

19. Смирнов П. Р., Тростин В. Н. Структурные параметры ближнего окружения ионов в водных растворах неорганических электролитов. Иваново, 2011, $400 \mathrm{c}$.

20. Кесслер Ю. М., Петренко В. Е., Лященко А. К. и др. / отв. ред. Кутепов А. М. Вода: структура, состояние, сольватация. Достижения последних лет. М.: Наука, 2003, 404 с.
21. Bonaccorsi R., Palla P., Tomasi J. // Journal of the American Chemical Society, 1984, vol. 106, № 7, pp. 1945 1950.

22. Gorbitz C. H. // Journal of the Chemical Society, Perkin Trans. 2, 1996, № 10, pp. 2213-2219.

23. Kusalik P. G., Bergman D., Laaksonen A. // Journal of Chemical Physics, 2000, vol. 113, № 18, pp. 80368046 .

24. Кручинин С. Е. Дисс. ... канд. хим. наук. Иваново, 2013, 155 с.

25. Max J.-J., Chapados C. // Journal of Physical Chemistry A, 2004, vol. 108, № 16, pp. 3324-3337.

26. Афанасьев В. Н., Тюнина Е. Ю., Рябова В. В. // Журнал структурной химии, 2004, т. 45, № 5, с. 883888.

27. White A., Jiang S. // Journal of Physical Chemistry $B$, 2011, vol. 115, № 4, pp. 660-667.

28. Королев В. П. // Журнал структурной химии, 2013, т. 54, № 3, с. 482-487.

29. Эрдей-Груз Т. Явления переноса в водных расmворах. М.: Мир, 1976, 595 с.

30. Кравцов В. И. Равновесие и кинетика электродных реакций комплексов металлов. М.: Химия, 1985, 208 с.

\title{
PHYSICAL AND CHEMICAL PROPERTIES OF SULPHATE-GLYCINE ZINC ELECTROPLATING SOLUTIONS
}

\author{
(C) 2017 E. V. Chentsova, S. U. Pochkina, N. D.Solov'yova \\ Engels Technological Institute of Yuri Gagarin State Technical University of Saratov, 17 Svoboda sq., \\ 413100 Engels, Saratov Region, Russia \\ e-mail:tepeti@mail.ru; ev-mail@rambler.ru;pochkina_s@mail.ru
}

Received 17.02.2017

\begin{abstract}
The interaction of components in sulphate-glycine solutions for the electroplating of zinc was studied with the content of $\mathrm{ZnSO}_{4} 0.05-0.25 \mathrm{~mol} / 1, \mathrm{NH}_{2} \mathrm{CH}_{2} \mathrm{COOH} 0.6-0.95 \mathrm{~mol} / \mathrm{l}$ and at the temperature range of $22-55{ }^{\circ} \mathrm{C}$. The dependence of electrical conductivity, optical density, kinematic viscosity and the enthalpy of a viscous flow on the solutions composition and the concentration of components was analysed. The physical and chemical properties of sulphate-glycine solutions used for electroplating of zinc are defined by the structural changes in these solutions. The changes occur due to the formation of zinc with glycine complexes. It was determined that with the zinc sulphate concentration range from 0.10 to $0.21 \mathrm{~mol} / \mathrm{l}$ and the glycine content of $0.7 \mathrm{~mol} / \mathrm{l}$, a complex is formed with a coordination number of $1-\mathrm{ZnGly}^{+}$. The stability of the complex formed depends on the temperature. The effect of the temperature on the structural transformations in the electrolyte is also indicated by a decrease in the enthalpy of a viscous flow from $\sim 7.3 \mathrm{~kJ} / \mathrm{mol}$ (temperature range $22-35{ }^{\circ} \mathrm{C}$ ) to $\sim 6.4 \mathrm{~kJ} / \mathrm{mol}$ (temperature range $40-55{ }^{\circ} \mathrm{C}$ ). The formation of ZnGly ${ }^{+}$type of complexes in the solutions used for electroplating zinc should facilitate the formation of uniform, finegrained coatings. Considering the formation of glycinate zinc complexes in the concentration range of $\mathrm{ZnSO}_{4}$ from 0.10 to $0.21 \mathrm{~mol} / \mathrm{l}$, as well as the value of the electrical conductivity and viscosity of the solutions studied, the following composition of the electrolyte is recommended: $\mathrm{ZnSO}_{4} 0.21 \mathrm{~mol} / \mathrm{l}$, $\mathrm{Na}_{2} \mathrm{SO}_{4} 0.5 \mathrm{~mol} / \mathrm{l}, \mathrm{NH}_{2} \mathrm{CH}_{2} \mathrm{COOH} 0.7 \mathrm{~mol} / \mathrm{l}$.
\end{abstract}

Keywords: zinc electroplating solution, glycine, electrical conductivity, optical density, an enthalpy of a viscous current, complex formation, coordination number. 


\section{REFERENCES}

1. Okulov V. V. Cinkovanie. Technique and Technology. Moscow, Globus Publ., 2008, 252 p. (in Russian)

2. Shehanov R. F., Gridchin S. N., Balmasov A. V., Rumjanceva K. E. Russian Journal of Chemistry and Chemical Technology [Izv. vuzov. Himija i himicheskaja tehnologija], 2015, vol. 58, no. 1, pp. 104-106. (in Russian)

3. Bobrikova I. G., Goncharenko E. G., Shahlevich E. S. Modern Tends in the Development of Science and Technology, 2016, no. 3-3, pp. 28-31. (in Russian)

4. Shmidt V. V., Zhihareva I. G., Rakashov A. A. Scientific and Technical «Volga Region Bulletin», 2015, no. 3, pp. 74-78. Available at: https://elibrary.ru/download/elibrary_23930413_17810952.pdf(accessed 21.09.2017). (in Russian)

5. Micin S., Martinez S., Malinovic B., Grozdanic V. Journal of Chemical Technology and Metallurgy, 2016, vol. 51, no. 5, pp. 556-562. Available at: http://dl.uctm. edu/journal/node/j2016-5/9-Micin_556-562.pdf (accessed 21.09.2017).

6. Berezin N. B., Berezina T. N., Mezhevich Zh. V., Sysoev V. A. Bulletin of the Technological University, 2014, vol. 17, no. 22, pp. 355-359.

7. Petrushova O. Ju., Cupak T. E. Journal Adnvances in Chemistry and Chemical Technology, 2014, vol. XXVIII, no. 5, pp. 95-97. Available at: http://acct.muctr.ru/media/ articles/pdf/2014_28_154_095-097.pdf (in Russian)

8. Dolgih O. V., Sockaja N. V., Shamanaeva E. S. Condensed Matter and Interphases, 2007, vol. 9, no. 1, pp. 3239. Available at: http://www.kcmf.vsu.ru/resources/t_09_1_ 2007_006.pdf (in Russian)

9. Sapronova L. V., Sockaja N. V., Dolgih O. V. Condensed Matter and Interphases, 2013, vol. 15, no. 4, pp. 446-452. Available at: http://www.kcmf.vsu.ru/resources/t_15_4_2013_013.pdf (in Russian)

10. Berezin N. B., Berezina T. N., Mezhevich Zh. V., Chevela V. V. Bulletin of the Technological University, 2013, vol. 16, no. 5, pp. 267-268.

11. Kozihonov A. U., Dzhulaev U. N., Radzhabov U. R., Shukhratzoda M., Bobiev G. M. Reports of the Academy of Sciences of the Republic of Tajikistan, 2015, vol. 58, no. 7, pp. 608-614. Available at: https://elibrary.ru/download/elibrary_25600373_69170663.pdf (accessed 21.09.2017)

12 . Berezin N. B., Gudin N. V., Filippova A. G., Chevela V. V., Mezhevich Zh. V., Jah'jaev Je. D., Sagdeev K. A. Electrodeposition of Metals and Alloys from Aqueous Solutions of Complex Compounds. Kazan, Kazan. State. Technol. University Publ., 2006, 276 p. (in Russian)

13. Mezhevich Zh. V., Berezin N. B. Bulletin of the Technological University, 2016, vol. 19, no. 9, pp. 51-53.

14. Krashhenko T. G., Vvedenshij A. V., Bobrinskaja E. V., Kuleshova N. E. Condensed Matter and Interphases, 2014, vol. 16, no. 1, pp. 42-49. Available at: http://www.kcmf. vsu.ru/resources/t_16_1_2014_007.pdf(in Russian)

15. Hohlov V. Ju, Selemenev V. F., Hohlova O. N, Zagorodnij A. A. Proceedings of Voronezh State University.
Series: Chemistry. Biology. Pharmacy, 2003, no. 1, pp. 1822. Available at: http://www.vestnik.vsu.ru/pdf/chembio/2003/01/hohlov.pdf (in Russian)

16. Bobreshkova O. V., Polumestnaya K. A., Fedosova A. A. Russian Journal of Electrochemistry, 2009, vol. 45, no. 3, pp. 345-349. DOI: 10.1134/S1023193509030161

17. Abrosimov V. K., Korolev V. V., Afanas'ev V. N., at al. Experimental Methods of Solution Chemistry: Densitometry, Viscosimetry, Conductometry and other Methods. Moscow, Science Publ., 1997, 351 p. (in Russian)

18. Solov`eva N. D., Frolova I. I., Legkaya D. A. Condensed Matter and Interphases, 2014, vol. 16, no. 2, pp. 201-205. Available at: http://www.kcmf.vsu.ru/resources/t_16_2_2014_013.pdf (in Russian)

19. Smirnov P. R., Trostin V. N. Structural Parameters of the Near Environment of Ions in Aqueous Solutions of Inorganic Electrolytes. Ivanovo, Ivanovo Publishing House, 2011, 400 p. (in Russian)

20. Kessler Ju. M., Petrenko V. E., Ljashhenko A. K., at al. / Ed. by Kutepov A. M. Water: Structure, Condition, Solvation. Achievements of Recent Years. Moscow, Science Publ., 2003, 404 p. (in Russian)

21. Bonaccorsi R., Palla P., Tomasi J. Journal of the American Chemical Society, 1984, vol. 106, no. 7, pp. 19451950. DOI: 10.1021/ja00319a008 Available at: http://pubs. acs.org/doi/abs/10.1021/ja00319a008 (accessed 21.09.2017)

22. Gorbitz C. H. Journal of the Chemical Society, Perkin Trans. 2, 1996, no. 10, pp. 2213-2219. DOI: 10.1039/ P29960002213 Available at: http://pubs.rsc.org/-/content/ articlepdf/1996/p2/p29960002213 (accessed 20.09.2017)

23. Kusalik P. G., Bergman D., Laaksonen A. Journal of Chemical Physics, 2000, vol. 113, no. 18, pp. 8036-8046. DOI: 10.1063/1.1315321 Available at: http://aip.scitation. org/doi/10.1063/1.1315321 (accessed 10.09.2017)

24. Kruchinin S. E. Thesis of Diss. ... Cand. Chem. Sci. Ivanovo, 2013, 155 pp. (in Russian)

25. Max J.-J., Chapados C. Journal of Physical Chemistry $A, 2004$, vol. 108, no. 16, pp. 3324-3337. DOI: 10.1021/jp036401t Available at: http://pubs.acs.org/doi/ abs/10.1021/jp036401t (accessed 10.09.2017).

26. Afanas'ev V. N., Tjunina E. Ju., Rjabova V. V. Journal of Structural Chemistry, 2004, vol. 45, no. 5, pp. 838-843. Available at: https://link.springer.com/content/ pdf/10.1007\%2Fs10947-005-0066-x.pdf

27. White A., Jiang S. Journal of Physical Chemistry $B$, 2011, vol. 115, no. 4, pp. 660-667. DOI: 10.1021/ jp1067654 Available at: http://pubs.acs.org/doi/abs/10.1021/ jp1067654 (accessed 21.09.2017)

28. Korolev V. P. Journal of Structural Chemistry, 2013, vol. 54, no. 3, pp. 534-540. DOI: 10.1134/S00224766130 30098

29. Erdey-Gruz T. Transport Phenomena in Aqueous Solutions. Budapest, Akademiai Kiado Publ., 1974.

30. Kravtsov V. I. Equilibrium and Kinetics of Electrode Reactions of Metal Complexes. Moscow: Chemistry Publ., 1985, 208 p. (in Russian) 
Ченцуова Елена Викторовна - к. х. н., доцент кафедры технологии и оборудование химических, нефтегазовых и пищевых производств, Энгельсский технологический институт (филиал) ФГБОУ ВО «Саратовский государственный технический университет имени Ю. А. Гагарина; тел.: +7(8453) 953553, e-mail: ev-mail@rambler.ru

Почкина Светлана Юрьевна - аспирант кафедры химии и химической технологии материалов, ФГБОУ ВО «Саратовский государственный технический университет имени Ю. А. Гагарина»; тел.: +7(909) 3396526 , e-mail: pochkina_s@mail.ru

Соловьева Нина Дмитриевна - д. т. Н., профессор кафедры технологии и оборудование химических, нефтегазовых и пищевых производств, Энгельсский технологический институт (филиал) ФГБОУ ВО «Саратовский государственный технический университет имени Ю. А Гагарина»; тел.: +7(8453) 953553, e-mail: tepeti@, mail.ru
Chentsova Elena. V. - Cand. Sci. (Chem.), Associate Professor, Department of Technologies and Equipment of Chemical, Oil-gas and Food Industries, Engels Technological Institute of Yuri Gagarin State Technical University of Saratov; ph.: +7(8453) 953553, e-mail: ev-mail@rambler.ru

Pochkina Svetlana Yu. - graduate student, Department of Technologies and Equipment of Chemical, Oil-gas and Food Industries, Engels Technological Institute of Yuri Gagarin State Technical University of Saratov; ph.: +7(909) 3396526, e-mail: pochkina_s@mail.ru

Solov'yova Nina D. - Dr. Sci. (Eng.), Professor, Department of Technologies and Equipment of Chemical, Oil-gas and Food Industries, Engels Technological Institute of Yuri Gagarin State Technical University of Saratov; ph.: +7(8453) 953553, e-mail: tepeti@mail.ru

\section{СООБЩЕНИЕ ОБ ОТЗЫВЕ АВТОРА ИЗ ПУБЛИКАЦИИ}

На заседании Редакционной коллегии от 12 декабря 2017 г. принято решение об исключении Розанцева Г. М. из авторов С. М. Вавилова, М. А. Крючков, В. В. Игнатьева, Е. Е. Белоусова статьи «АНАЛИЗ СОСТОЯНИЯ ИЗОПОЛИНИОБОВОЛЬФРАМАТ-АНИОНОВ $(\mathrm{Nb}: \mathrm{W}=3: 3)$ И СИНТЕЗ ИХ СОЛЕЙ ИЗ ВОДНЫХ РАСТВОРОВ», опубликованной в журнале «Конденсированные среды и межфазные границы», 2017, том 19, № 3, с. 341-351.

Основанием является письмо и.о. ректора Донецкого национального университета имени Васыля Стуса Р. Ф. Гринюка о том, что сотрудник этого университета - профессор Г. М. Розанцев не давал своего согласия и не принимал участия в написании данной статьи.

\section{NOTIFICATION ON THE AUTHOR RETRACTION FROM PUBLICATION}

At the meeting of Editorial Board on December 12, 2017 it was made a decision to retract G. M. Rozantsev from the authors of paper S. M. Vavilova, M. A. Kryuchkov, V. V. Ignatyeva, E. E. Belousova «ANALYSIS OF THE STATE OF ISOPOLYNIOBOTUNGSTATE ANIONS (Nb:W = 3:3) AND THEIR SYNTHESIS FROM AQUEOUS SOLUTIONS» CONDENSED MATTER AND INTERPHASES. 2017, vol. 19, no. 3, pp. 341-351.

This decision is based on the letter of R. F. Grinyuk, acting Rector of Donetsk National University named after Vasyl Stus, reported that an employee of this university Professor G. M. Rosantsev did not give his consent and did not participate in the writing of this paper. 